\title{
Blood transfusion services
} amidst the COVID-19 pandemic

\section{Siti Salmah Noordin ${ }^{1}$, Narazah Mohd Yusoff ${ }^{1}$, Faraizah Abdul Karim²,3, Soon Eu Chong ${ }^{1,4,5}$}

\author{
${ }^{1}$ Cluster of Regenerative Medicine, Advanced Medical and Dental Institute, Universiti Sains Malaysia, Kepala Batas, Malaysia \\ ${ }^{2}$ Hemophilia Clinic, National Blood Centre, Kuala Lumpur, Malaysia \\ ${ }^{3}$ Hospital Ampang, Ministry of Health Malaysia, Selangor, Malaysia \\ ${ }^{4}$ Department of Anaesthesiology and Intensive Care, School of Medical Sciences, Universiti Sains Malaysia, Kelantan, Malaysia \\ ${ }^{5}$ Hospital USM, Health Campus, USM, Kubang Kerian, Kelantan, Malaysia
}

\section{Blood transfusion services have been impacted by this COVID-19 pandemic. This includes the concerns regarding blood donation safety and blood prod- uct supply chains, abetted by the fear and stigmatisation of healthcare workers in the handling of COVID-19 samples.}

\begin{abstract}
T
\end{abstract} he year 2020 marked the beginning of a major change in the way we humans live and interact due to the COVID-19 pandemic $[1,2]$. The causative agent of this disease is severe acute respiratory syndrome coronavirus 2 (SARS-CoV-2). Due to the relatively mild symptoms in the early phase of infection, a long incubation period and a high infectivity rate, SARS-COV-2 has spread at lightning speed globally. To date, the number of COVID-19 cases has exceeded 120 million globally and continues to rise exponentially with a fatality ratio of $0.5 \%-1.0 \%$, and this ratio increases with age. Despite headlines on COVID-19 vaccines and treatments, the ability of the virus to mutate leaves many uncertainties particularly with regard to the efficacies of vaccines and treatments.

Healthcare services, including blood transfusion, have been significantly affected. This review aims to discuss the impact and suggest the best practice for transfusion services in this era of new norms (Figure 1).

\section{DONATION SAFETY}

\section{Blood donors}

Blood donations have decreased dramatically by $40 \%$ to $67 \%$ during this outbreak of COVID-19, particularly in countries where restriction of movement is enforced [3]. Potential blood donors face difficulties to access donation sites and fear of contracting the virus along the way. In addition, most mobile blood drives have been cancelled.

To address this problem, continuous public appeals for donation through both mainstream and social media are crucial coupled with reassurances on safety measures taken throughout the process. Blood centres can actively approach potential blood donors via emails, text messages or phone calls. These telemedicinal approaches can also be used as a first health screening to ensure that only suitable donors turn up for donation and allowing personalised donation slots to be arranged. Transportation may also be provided for donors. 


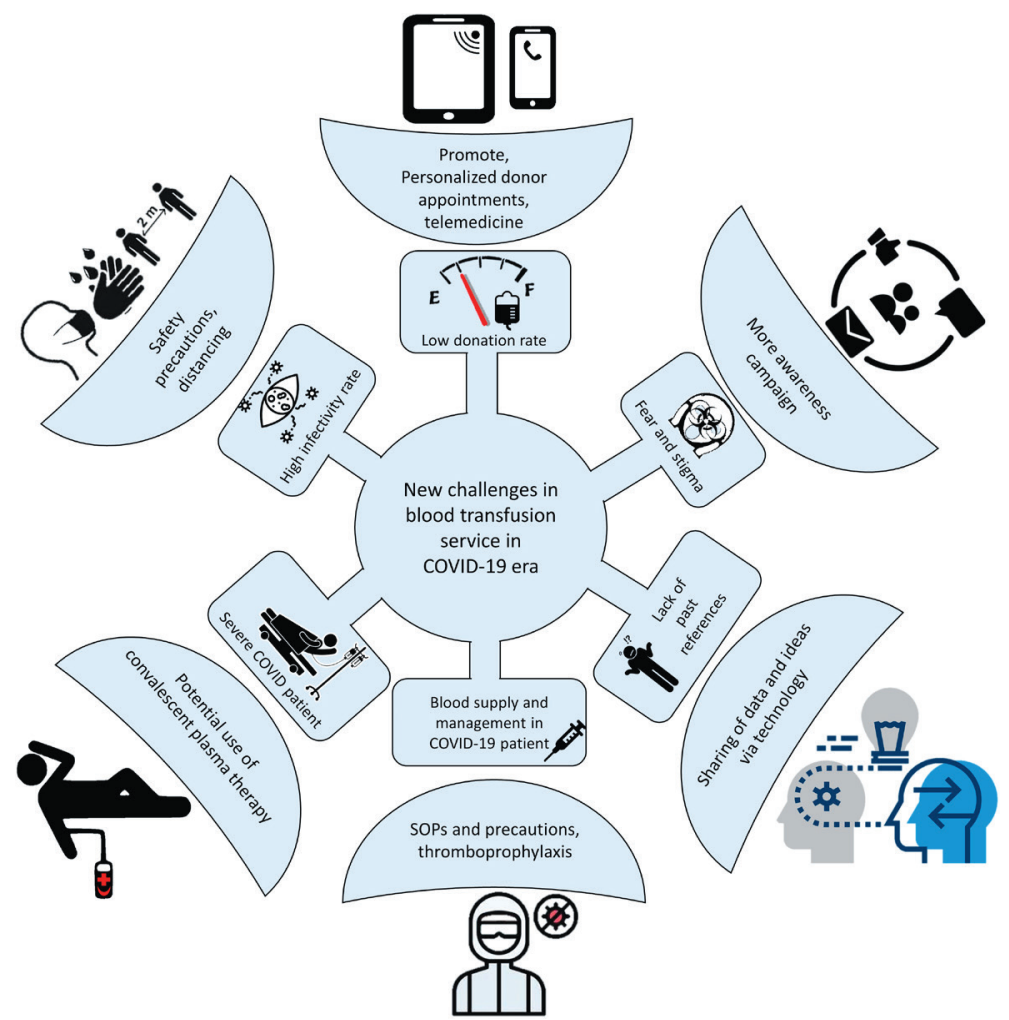

Figure 1. New challenges in blood transfusion services in COVID-19 era and suggested steps to establish. SOP, standard operating procedures.
Stringent donation criteria should be implemented. A 14-day deferral from donation should be applied to those who have recovered from COVID-19 and those who have received live-attenuated COVID-19 vaccines.

\section{Blood collection sites}

Healthcare workers (HCWs) are not spared from being infected by COVID-19. A meta-analysis estimated that the prevalence of SARS-CoV-2 infection among HCWs is about 7\%-11\% [4]. Thus, HCWs should strictly adhere to infection control practices during this pandemic. (Figure 2)

In blood donation areas, chairs need to be rearranged in accordance with physical distancing guidelines. High-touch areas and equipment should be frequently disinfected. The recommendation of ventilating blood donation areas twice a day for not less than 30 minutes each time should also be followed [5].

\section{BLOOD PRODUCT SAFETY}

SARS-CoV-2 is transmitted mainly through respiratory droplets and direct contacts. To date, there has been no reported case of blood transfusiontransmitted COVID-19 even among patients who were transfused with blood from donors that was found to be positive for COVID-19 [6,7]. However, concerns and anxiety still persist among HCWs regarding the handling of COVID-19 blood samples.

Blood product screening for viruses may have a high false-negative rate which questions its usefulness, similar to what happened during the SARS outbreak $[8,9]$. Nevertheless, pathogen reduction (PR) on blood products using riboflavin and UV (UV) light has been shown to be effective in reducing SARSCoV-2 infectivity [10].

Other additional strategies to ensure the safety of blood products include prolonged quarantine of RBCs and plasma products for up to 14 days; this recommendation is based on a model estimation study which reported about $65.77 \%$ reduction risk of SARS-CoV-2 transmission through blood [11].

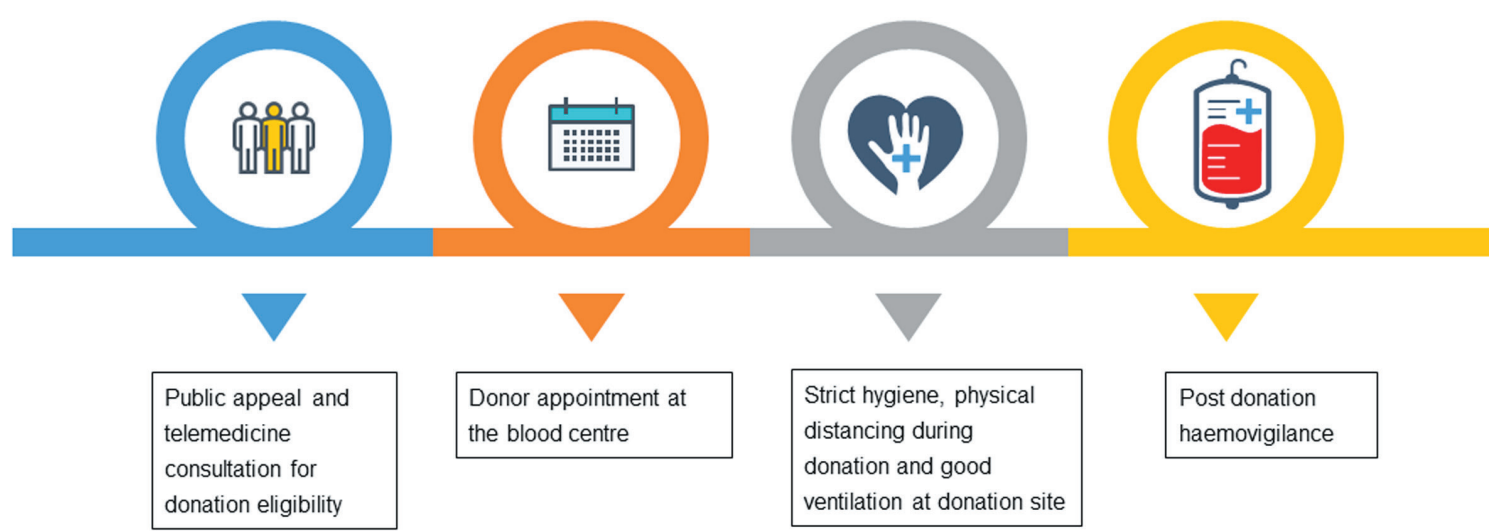

Figure 2. Blood donation activities during COVID-19 pandemic. 


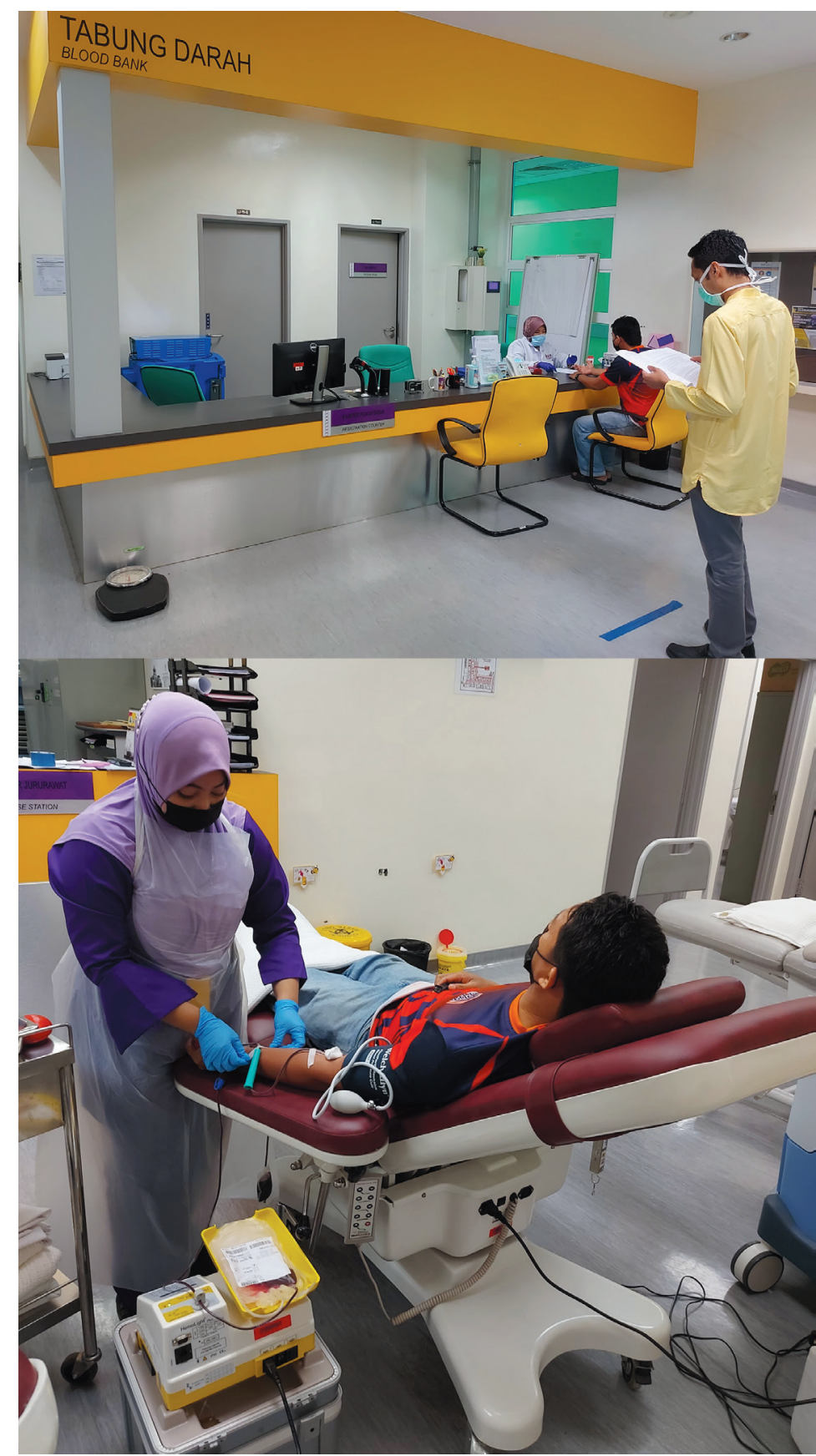

Photo: Malaysian blood bank operating in the COVID-19 pandemic by conforming to the new norms (from Siti Salmah Noordin and Ermarina Kamaruddin's collection, used with permission).
Active haemovigilance of blood donors and recipients must be emphasised. Any possibility of COVID-19 transmission via blood transfusion must be properly investigated. The use of information technology is important in the tracing of transfusion chains [12]. If blood donors are suspected or confirmed to have COVID-19, lookbacks and recall procedures should be performed on their donated blood products and their recipients.

\section{TRANSFUSION TESTING AND BLOOD SUPPLY FOR PATIENTS WITH COVID-19}

It has been reported that about $13.4 \%$ of hospitalised patients with COVID-19 received blood transfusion, and this number is lower than non-COVID-19 patients. RBCs remain the highest blood product transfused (11.1\%) [13]. Handling of blood samples from patients with suspected or confirmed COVID-19 should follow strict laboratory biosafety practices according to the national health recommendations. In view of the low concentration of virus in non-respiratory samples, blood tests can be performed under standard blood-borne pathogen biosafety level (BSL)-2 [14].

All samples and request forms for blood transfusion should be clearly labelled indicating the sample is from a COVID-19 patient. Triple-layer packaging is recommended for transporting the sample to the laboratory. The outer layer of biohazard plastic bag and container should be disinfected prior to transportation. In some centres, UV irradiation is used for disinfection prior to laboratory processing $[10,15]$.

Laboratory personnel who handle COVID-19 samples are required to wear full personal protective equipment (PPE) and process the samples in a biosafety cabinet. After each step of centrifugation, the samples should be left for at least 15 minutes to

avoid aerosolising of the content. Other steps of pre-transfusion testing can be performed according to standard operating procedures (SOP), with additional precaution on safe handling. After completion of testing and analysis, laboratory equipment should be decontaminated using proper disinfectants, such as ethanol (70\%95\%), isopropanol (50\%-100\%), 0.5\% hydrogen peroxide, $0.1 \%$ sodium hypochlorite and $0.7 \%$ glutaraldehyde (Figure 3).

In some blood transfusion services, test procedures such as group, screen and hold (GSH) and crossmatching will not be provided for COVID-19 patients. Should these patients require blood transfusions, uncrossmatched blood group $\mathrm{O}$ packed-RBCs, group $\mathrm{O}$ platelet or group $\mathrm{AB}$ plasma are supplied for transfusion for those who have no history of sensitisation. However, transfusion should be performed with caution because of the risk of non-ABO mediated alloantibody which may lead to delayed transfusion reaction. Nevertheless, shortages of group $\mathrm{O}$ RBCs for group $\mathrm{O}$ patients should be anticipated if all patients with COVID-19 are routinely supplied through this approach. 


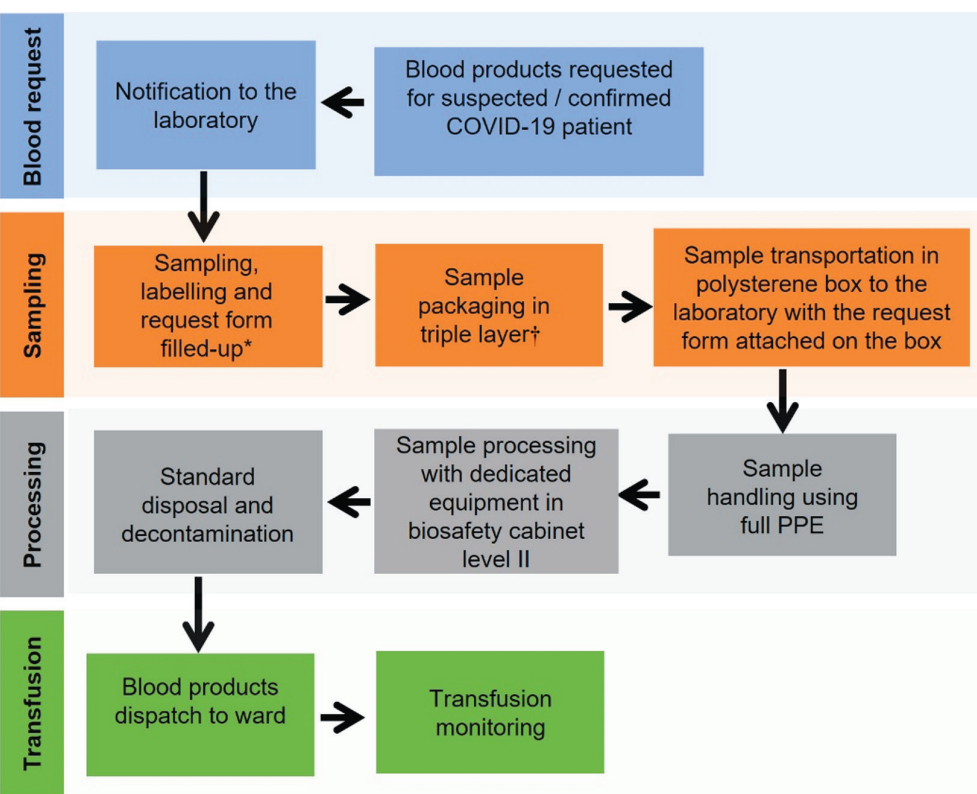

Figure 3. Transfusion process for suspected or confirmed case of COVID-19. PPE, personal protective equipment: disposable gown, gloves, N95 masks, eye goggles or face shields, work caps, shoe covers and plastic aprons. *Both sample tubes and request forms should state 'COVID-19 sample'. †Triple layer packaging: sample tube seal with paraffin film, wrapping the tube with gauze and tightened it with rubber band (first layer), placement of the tube into two consecutive biohazard bags (second and third layer). Disinfect the outer biohazard bag with $70 \%$ alcohol.
Coagulopathy in patients with severe COVID-19

Among patients with severe COVID-19, cytokine storms and liver injury may predispose them to coagulopathy. Severe cases of COVID-19 may present as pneumonia and sepsis. These conditions may produce hyperactive $\mathrm{T}$ lymphocytes, massive release of interleukin- 6 and interleukin-1, which contribute to a cytokine storm. These phenomena lead to extensive tissue damage, endothelial injury and release of tissue factors that may promote a widespread thrombin generation, leading to disseminated intravascular coagulopathy (DIC).

The up-regulation of angiotensin-converting enzyme 2 (ACE2) expression in liver tissues caused by compensatory hepatocyte proliferation may also lead to COVID-19-related liver injury [16]. Severe liver tissue injury in turn reduces the production of vitamin K-dependent coagulation factors, protein $\mathrm{C}$ and protein $\mathrm{S}$, resulting in coagulopathy.

Interestingly, the abnormal coagulation parameters in severe COVID-19 infection do not often lead to bleeding. Transfusion of blood components should only be reserved for coagulopathic patients with high risk of bleeding or requiring invasive procedures. Replacement of blood products by relying solely on laboratory parameters might worsen the disseminated thrombosis.

In view of the prothrombotic state, prophylactic dose of low-molecular-weight heparin is generally recommended for most of hospitalised patients with COVID-19, irrespective of prothrombin time or activated partial thromboplastin time, unless the platelet counts are below $25 \times 10^{9} / \mathrm{L}$ or fibrinogen level is below 0.5 $\mathrm{g} / \mathrm{L}$. Mechanical thromboprophylaxis should be employed in cases where pharmacological therapy is contraindicated.

\section{CONVALESCENT PLASMA THERAPY}

Thus far, efforts in finding the best treatment for COVID-19 is still ongoing. Convalescent plasma (CP) and hyperimmune immunoglobulin has been used as a potential treatment for patients with COVID-19 who do not respond well to other treatments. These treatments involve passive transfer of antibodies collected from donors who have recovered from prior infection. Therapy with CP provides neutralising antibodies and other proteins which may ameliorate severe inflammatory response through immunomodulation [17]. The use of passive immunisation as a treatment for infection is not a new technology and can be dated back to the 1890s, whereby serum was used to treat diphtheria. For the past two decades, CP has been successfully administered to treat SARS, influenza A and Middle East Respiratory Syndrome.

Several criteria are required for donor recruitment to ensure the safety of CP products. Such criteria include donors with confirmed RT-PCR for SARS-CoV-2, tested negative for SARS-CoV-2 after at least 14 days of symptoms resolution, anti-SARS-Cov-2 neutralising antibody activity titre minimum of 1:40 and tested negative on all the standard microbiology screening tests [18]. Plasma is collected via apheresis with volume of approximately $600 \mathrm{~mL}$, and the process can be performed every two weeks.

At present, no standard dose for $\mathrm{CP}$ has been established, but administering $3 \mathrm{~mL} / \mathrm{kg}$ per dose within two days is generally recommended. Clinical trials showed that the effectiveness of $\mathrm{CP}$ and hyperimmune immunoglobulin against COVID-19 are still uncertain [19]. Some trials were discontinued prematurely either due to lack of samples or patient safety issues. 


\section{CONCLUSION}

Apart from ensuring the safety of donors, HCWs and patients, encompassing technology in the management of blood transfusion service and the sharing of latest updates are important contributions to the improvement of health care services in this COVID-19 era.

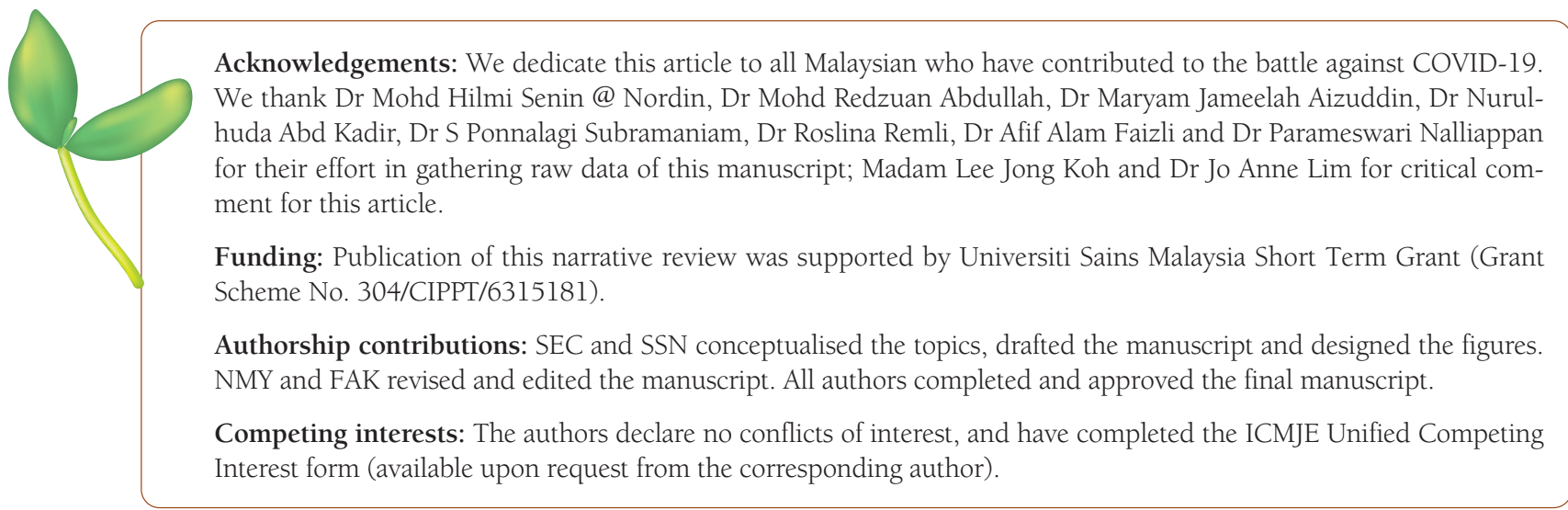

1 Armocida B, Formenti B, Palestra F, Ussai S, Missoni E. COVID-19: Universal health coverage now more than ever. J Glob Health. 2020;10:010350. Medline:32426119 doi:10.7189/jogh.10.010350

2 Nagesh S, Chakraborty S. Saving the frontline health workforce amidst the COVID-19 crisis: Challenges and recommendations. J Glob Health. 2020;10:010345. Medline:32373323 doi:10.7189/jogh.10.010345

3 Raturi M, Kusum A. The blood supply management amid the COVID-19 outbreak. Transfus Clin Biol. 2020;27:147-51. Medline:32386966 doi:10.1016/j.tracli.2020.04.002

4 Gómez-Ochoa SA, Franco OH, Rojas LZ, Raguindin PF, Roa-Diaz ZM, Wyssmann BM, et al. COVID-19 in Health-Care Workers: A Living Systematic Review and Meta-Analysis of Prevalence, Risk Factors, Clinical Characteristics, and Outcomes. Am J Epidemiol. 2021;190:161-75. Medline:32870978 doi:10.1093/aje/kwaal91

5 Zhang X, Liang X, Qi H, Liu Q, Lin J, Zhang Y, et al. Recommendations for Blood Establishments Regarding the Novel Coronavirus Disease (COVID-19) Outbreak (v1.0). 2020. Available: https://eng.csbt.org.cn/portal/article/index/id/606/cid/7.html. Accessed: 7 August 2020.

6 Cho HJ, Koo JW, Roh SK, Kim YK, Suh JS, Moon JH, et al. COVID-19 transmission and blood transfusion: A case report. J Infect Public Health. 2020;13:1678-9. Medline:32405329 doi:10.1016/j.jiph.2020.05.001

7 Kwon SY, Kim EJ, Jung YS, Jang JS, Cho NS. Post-donation COVID-19 identification in blood donors. Vox Sang. 2020;115:6012. Medline:32240537 doi:10.1111/vox.12925

8 Cheng PK, Wong DA, Tong LK, Ip SM, Lo AC, Lau CS, et al. Viral shedding patterns of coronavirus in patients with probable severe acute respiratory syndrome. Lancet. 2004;363:1699-700. Medline:15158632 doi:10.1016/S0140-6736(04)16255-7

9 Merola J, Schilsky ML, Mulligan DC. The Impact of COVID-19 on Organ Donation, Procurement, and Liver Transplantation in the United States. Hepatol Commun. 2020;5:5-11. Medline:33043228 doi:10.1002/hep4.1620

10 Ragan I, Hartson L, Pidcoke H, Bowen R, Goodrich R. Pathogen reduction of SARS-CoV-2 virus in plasma and whole blood using riboflavin and UV light. PLoS One. 2020;15:e0233947. Medline:32470046 doi:10.1371/journal.pone.0233947

11 Yuan Z, Chen D, Chen X, Wei Y. Estimation of the number of blood donors during the COVID-19 incubation period across China and analysis of prevention and control measures for blood transfusion transmission. Transfusion. 2020;60:1778-84. Medline:32442333 doi:10.1111/trf.15858

12 Ramoa A, Condeço J, Escoval MA, Faber J-C, Fdez-Riverola F, Lourenço A. The Evolving Role of Information Technology in Haemovigilance Systems. J Healthc Eng. 2018;2018:6183468. Medline:29707185 doi:10.1155/2018/6183468

13 Barriteau CM, Bochey P, Lindholm PF, Hartman K, Sumugod R, Ramsey G. Blood transfusion utilization in hospitalized COVID-19 patients. Transfusion. 2020;60:1919-23. Medline:32583506

14 Chang L, Yan Y, Wang L. Coronavirus Disease 2019: Coronaviruses and Blood Safety. Transfus Med Rev. 2020;34:75-80. Medline:32107119 doi:10.1016/j.tmrv.2020.02.003

15 Ministry of Health Malaysia. Packaging and Transporting of Infectious Substances and Diagnostic Specimens. 2018 Available: https://mkak.moh.gov.my/ms/muat-turun/borang-dokumen-bahagian-penyakit/lain-lain-dokumen.html\#. Accessed: 20h August 2020.

16 Guan WJ, Ni ZY, Hu Y, Liang WH, Ou CQ, He JX, et al. Clinical Characteristics of Coronavirus Disease 2019 in China. N Engl J Med. 2020;382:1708-20. Medline:32109013 doi:10.1056/NEJMoa2002032 
17 Rojas M, Rodriguez Y, Monsalve DM, Acosta-Ampudia Y, Camacho B, Gallo JE, et al. Convalescent plasma in Covid-19: Possible mechanisms of action. Autoimmun Rev. 2020;19:102554. Medline:32380316 doi:10.1016/j.autrev.2020.102554

18 Tiberghien P, de Lamballerie X, Morel P, Gallian P, Lacombe K, Yazdanpanah Y. Collecting and evaluating convalescent plasma for COVID-19 treatment: why and how? Vox Sang. 2020;115:488-94. Medline:32240545 doi:10.1111/vox.12926

19 Piechotta V, Chai KL, Valk SJ, Doree C, Monsef I, Wood EM, et al. Convalescent plasma or hyperimmune immunoglobulin for people with COVID-19: a living systematic review. Cochrane Database Syst Rev. 2020;7:CD013600. Medline:32648959

\section{Correspondence to:}

Soon Eu Chong, MD, MMed

Department of Anaesthesiology and Intensive Care Hospital USM

School of Medical Sciences

Universiti Sains Malaysia

Kelantan

Malaysia

sechong@usm.my

Siti Salmah Noordin, MD, MMed

Cluster of Regenerative Medicine

Advanced Medical and Dental Institute

Universiti Sains Malaysia

Penang

Malaysia

ssalmah@usm.my 